\title{
Dipterocarp seedling population dynamics in Bornean primary lowland forest during the 1997-8 El Niño-Southern Oscillation
}

\author{
Daniel P. Bebber*1, Nick D. Brown* and Martin R. Speight†
}

*Department of Plant Sciences, South Parks Road, Oxford OX1 3RB, UK

†Department of Zoology, South Parks Road, Oxford OX1 3PS, UK

(Accepted 10 December 2002)

\begin{abstract}
Dipterocarp seedling populations arising from a 1996 mast fruiting in closed-canopy primary lowland rain forest in Sabah, Malaysia, were monitored through the 1997-8 El Niño event to investigate the effects of drought and other factors on dipterocarp regeneration. Of particular interest was the influence of herbivory and its relation to drought, since water stress is known to influence herbivore performance. For seedlings with less than $10 \%$ leaf damage, mortality during a 6-mo period spanning the driest part of the drought was three times higher than mortality in the previous and subsequent 6 -mo periods $(\sim 10 \%$ vs. $\sim 30 \%)$. Leaf production was also higher during this period. Survival was positively related to leaf number and negatively related to leaf damage. Dryobalanops lanceolata was the tallest and leafiest species, and had low levels of leaf damage. Depending on sample period, abscission of leaves with more than 50\% damage was between two and three times more likely than those with less than $10 \%$ damage. Mortality of seedlings defoliated by more than $50 \%$ was around twice that of seedlings defoliated by less than $10 \%$. However, fewer than $10 \%$ of seedlings were defoliated by more than $50 \%$ at any time. The effect of defoliation did not seem to be altered by drought. Defoliation levels increased after the drought, perhaps due to a resurgence of insect populations. Drought may become a more important influence on dipterocarp regeneration in future, since El Niño events are thought to be increasing in frequency.
\end{abstract}

Key Words: Dipterocarpaceae, drought, ENSO, herbivory, Malaysia, Sabah

\section{INTRODUCTION}

The climatic phenomenon known as the El Niño-Southern Oscillation (ENSO) is thought to be increasing in frequency and severity (Timmermann et al. 1999). Among its many influences across the globe (Glynn 1988, Holmgren et al. 2001), ENSO causes severe droughts and associated fires across South-East Asia (Walsh \& Newbery 1999). Though secondary forests are particularly susceptible to fires due to increased fuel load, drier microclimate and deliberate fire setting (Brown 1998, Woods 1989), tree mortality in primary lowland dipterocarp forest is also elevated by drought (Becker et al. 1998, Nakagawa et al. 2000).

Trees in the family Dipterocarpaceae vary in their growth characteristics, from fast-growing, lightdemanding species to slow-growing, shade-tolerant ones (reviewed in Whitmore 1984). Such variation may influence drought susceptibility in adult trees via differences in xylem structure (Bebber 2002), and in seedlings via characteristics such as root:shoot allocation and water-use efficiency (reviewed in Turner 2001).

\footnotetext{
${ }^{1}$ Corresponding author. Email: danbebber@yahoo.co.uk
}

Shade-tolerance in seedlings is often related to increased leaf longevity and leaf toughness, reducing losses of scarce resources where light availability is limiting (Coley \& Barone 1996, Coley et al. 1985). Though defoliation is relatively insignificant to the majority of dipterocarp seedlings (Becker 1983, Blundell \& Peart 2000), herbivores have been shown to alter competitive interactions between seedlings (Whitmore \& Brown 1996) and may be involved in distance-dependent mortality of seedlings (Blundell \& Peart 1998, Webb \& Peart 1999). Drought can alter plant palatability and defence, and performance of insect herbivores (Mattson \& Haack 1987). Meta-analyses of large numbers of studies indicate that though responses of any one plant-insect relationship can be idiosyncratic, leaf chewers and suckers tend to be negatively affected by plant drought stress, while borers are positively influenced (Koricheva et al. 1998, Waring \& Cobb 1992).

Differences in seedling persistence in the understorey are thought to maintain high diversity in dipterocarps (Brown et al. 1999). In this study, populations of dipterocarp seedlings arising from a 1996 mast-fruiting were followed through the 1997-8 ENSO, in order to gain a better understanding of the influence of drought and herbivory 


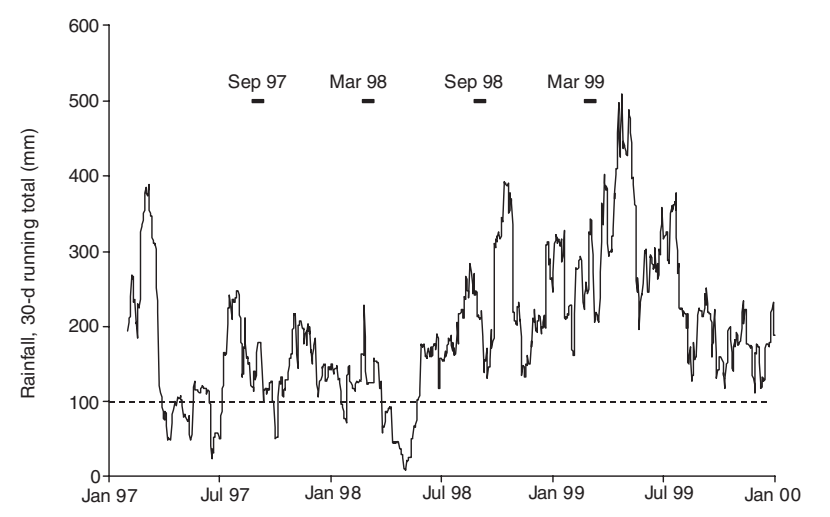

Figure 1. Danum Valley Field Centre rainfall ( $\mathrm{mm}), 30-\mathrm{d}$ running totals, January 1997 to January 2000. The estimated transpirational threshold is indicated at $100 \mathrm{~mm}$. Dashes (-) show the census periods.

on seedling performance. It was expected that defoliation levels would be reduced during drought due to poorer performance of leaf chewers, but that less shade-tolerant seedlings would be weakened by drought and would be more susceptible to herbivore damage.

\section{STUDY SITE}

The study was conducted in lowland dipterocarp forests of the Danum Valley Conservation Area, Sabah, East Malaysia, $4^{\circ} 58^{\prime} \mathrm{N}, 117^{\circ} 48^{\prime} \mathrm{E}$. The $438-\mathrm{km}^{2}$ Conservation Area is surrounded by a mosaic of secondary forest at various stages of regeneration after logging. The forest lies $70 \mathrm{~km}$ inland of the east coast of Borneo, at around $200 \mathrm{~m}$ asl. Soils are orthic acrisols formed over a melange of slumped sedimentary and volcanic rocks (Marsh \& Greer 1992), and the topography is undulating.

Mean annual rainfall is around $2800 \mathrm{~mm}$ but with large annual and interannual variations that include droughts related to El Niño (Walsh \& Newbery 1999). Drought in tropical wet forests is usually said to occur when less than $100 \mathrm{~mm}$ of rain falls within a month, since this is the estimated rate of transpiration (Walsh 1996). The 1997-8 drought manifested itself as a sporadic dry period between April and July 1997, and a more sustained dry period between March and June 1998 (Figure 1). Only $11 \mathrm{~mm}$ of rain fell during April 1998 in the Danum Valley. Rainless periods lasting between 10 and 13 d occurred in late September 1997, late January 1998, mid March 1998 and mid April 1998.

\section{METHODS}

Within the Danum Valley Conservation Area, four study sites with a pronounced ridge topography and closed canopy were selected. Between eight and ten $1 \times 1-\mathrm{m}$ permanent quadrats were placed randomly within ridge, slope and valley strata, giving 84 plots in total. Slope plots were not placed within the two smallest sites because of insufficient space. Quadrats were marked with painted plastic poles and tape. In February 1999, hemispherical canopy photographs were taken at $50 \mathrm{~cm}$ above the centre of each quadrat using a Nikon 8-mm fish-eye lens and Kodacolor Gold III ISO 100 colour film in a Nikon manual camera. The photographs were analysed using Hemiview Canopy Analysis Software version 2.0 beta 1 from Delta-T devices (http://www.delta-t.co.uk). Global Site Factor (GSF), the proportion of global radiation under the plant canopy relative to that in the open, was calculated from the photographs.

Dipterocarps flower gregariously over a wide geographic area (Appanah 1993). These mast fruitings occur every 2-10 y, and seem to be related to ENSO (Curran et al. 1999, Yasuda et al. 1999). A mast fruiting of dipterocarps had occurred in the third quarter of 1996 in the Danum Valley Conservation Area, seedlings of which were monitored during the study. These were distinguished from older seedlings by their small size, smooth thin bark, and small number of leaves and leaf scars.

Four seedling censuses were undertaken, in September 1997, March 1998, September 1998 and March 1999. The period between each census was kept as constant as possible, to within a few days. The first inter-census period spanned an intermittently dry spell that followed the first period of ENSO-related drought in May to July 1997 (Figure 1). The second inter-census period spanned the extremely dry month of April 1998. The third period was characterized by high precipitation.

At the first census, each dipterocarp seedling was individually identified with a numbered plastic tag. At the first and each subsequent census, each leaf was numbered in permanent pen on the underside near the petiole, barring small flushing leaves that were too delicate to mark. The occurrence of flushing leaves was noted, however. Leaf scars of leaves that had been flushed and abscised between censuses were recorded. The length of fully expanded leaves was measured from the base of the lamina to the beginning of the drip-tip. Seedling height was measured from the ground to the highest growing point, any peculiarity of growth form being noted. Percentage damage in various categories was estimated by eye, as was the number of mines, eggs and galls. Loss of expanded leaves that were present at the previous census was attributed to abscission, and not used to calculate overall defoliation rate. Dead tagged seedlings were carefully removed from the soil and inspected for evidence of what may have caused their death.

Leaf areas were estimated from length using a quadratic regression $\left(A=b \mathrm{x}^{2}\right)$. Species-specific relationships were developed using 20 randomly selected, fully expanded leaves from 20 seedlings of each species in the study. These leaves were scanned into a personal computer, and length and area measured using Aequitas IA software 
(Dynamic Data Links, Cambridge, UK). A quadratic regression line was then fitted to the data for each species, constrained to an intercept of zero. Estimated areas were reduced by the observed level of leaf damage.

Since leaf damage values were estimated by eye, training in damage estimation was undertaken prior to the study. One hundred intact dipterocarp seedling leaves were picked and scanned into a personal computer. Leaf area of each leaf was measured using Aequitas IA software. A proportion of each leaf was then torn off and the leaves scanned and measured again, from which the actual amount missing was calculated. This ranged from $0.2 \%$ to $83.4 \%$. The leaves and the missing proportion data were then inspected, and $1 \mathrm{wk}$ later the proportion missing was estimated by eye. Linear regression of estimates against actual values gave a slope of $0.75 \pm 0.03\left(\mathrm{r}^{2}=\right.$ $0.82, \mathrm{P}<0.001)$. Since damage was overestimated, estimation was repeated to give a final slope of $0.94 \pm$ $0.03\left(r^{2}=0.90, P<0.001\right)$.

\section{RESULTS}

A total of 5590 leaves of 1150 dipterocarp seedlings in eight species was sampled in the course of the study: Dryobalanops lanceolata Burck $(\mathrm{n}=90)$, Parashorea $\mathrm{sp}$. ( $\mathrm{n}=451)$, Shorea acuminatissima Sym. ( $\mathrm{n}=55)$, S. argentifolia Sym. $(\mathrm{n}=10), S$. glaucescens W. Meijer $(\mathrm{n}=131)$, S. leprosula Miq. $(\mathrm{n}=3)$, S. johorensis Foxw. $(\mathrm{n}=298)$, S. parvifolia Dyer $(\mathrm{n}=106)$ and $S$. superba Sym. $(\mathrm{n}=6)$. Parashorea is not identified to species because the two species found at Danum, $P$. malaanonan (Blco.) Merr. and P. tomentella (Sym.) W. Meijer, cannot be reliably distinguished as seedlings (Meijer \& Wood 1964). Shorea leprosula, S. argentifolia and S. superba were not included in the analyses since 10 or fewer individuals were sampled. The following abbreviations will be used to identify species in Figures: $\mathrm{Dl}=D$. lanceolata, $\mathrm{Pa}=$ Parashorea spp., $\mathrm{Sa}=S$. acuminatissima, $\mathrm{Sg}=S$. glaucescens, $\mathrm{Sj}=S$. johorensis, $\mathrm{Sp}=S$. parvifolia, $\mathrm{All}=$ all species combined.

\section{Herbivory}

A number of different leaf-damage types were found, including galling, mining, chewing from the leaf edge, holes cut into the lamina, scraping, skeletonization and necrosis. Mines were most common in D. lanceolata and $S$. johorensis, whilst galls were most common in $D$. lanceolata (Figure 2, likelihood ratio test, $\mathrm{P}<0.05$ ). A distinctive leaf roller, in which leaves were rolled longitudinally and contained a small coleopteran larva, was found in $7 \%$ of Parashorea seedlings. Around one-sixth $(\mathrm{n}=189)$ of seedlings lost their apical meristems through the study, and of these three quarters $(n=146)$ grew a new shoot from a lateral bud. New apical meristem


Figure 2. Percentage of seedlings (a) mined and (b) galled, $\pm 95 \%$ confidence limits. Census 1 (unshaded), census 2 (cross-hatching), census 3 (diagonal hatching) and census 4 (vertical hatching). $\mathrm{Dl}=$ D. lanceolata, $\mathrm{Pa}=$ Parashorea spp., $\mathrm{Sa}=S$. acuminatissima, $\mathrm{Sg}=$ S. glaucescens, $\mathrm{Sj}=$ $S$. johorensis, $\mathrm{Sp}=S$. parvifolia. Missing bars indicate zero mean.

damage (i.e. discounting that found in seedlings in the first census) was significantly more frequent at the fourth census $(9 \%)$ than in the second $(3 \%)$ and third $(4 \%)$ censuses (likelihood ratio test, $\mathrm{P}<0.001$ ). The majority of regrowth occurred during the same 6-mo period as the loss of the apical meristem. Apical meristem damage in the first census was related to increased seedling mortality ( $26 \%$ vs. $14 \%$ in undamaged seedlings, likelihood ratio test, $\mathrm{P}=0.015)$. There was no relationship in subsequent censuses.

Standing levels of defoliation increased through the study as leaves accumulated damage (Figure 3a). Damage to newly flushed leaves was greater than that to expanded leaves (Wilcoxon signed ranks test, $\mathrm{P}<0.001$ ). The distribution of damage was highly skewed, with two-thirds of seedlings having less than the mean percentage defoliation. The overall defoliation rate, taking loss of whole leaves into account, was $0.03 \% \mathrm{~d}^{-1}$. Damage to newly flushed leaves and expanded leaves was greater during the last period than the previous ones (Wilcoxon signed ranks test, $\mathrm{P}<0.01)$. There were significant differences among species in damage to new leaves (Kruskal-Wallis test, $\mathrm{P}<$ 0.01 ), with $D$. lanceolata having consistently low damage (Figure 3b).

\section{Leaf dynamics}

Seedlings had up to 30 leaves, the number of leaves depending strongly on species and height (General Linear 

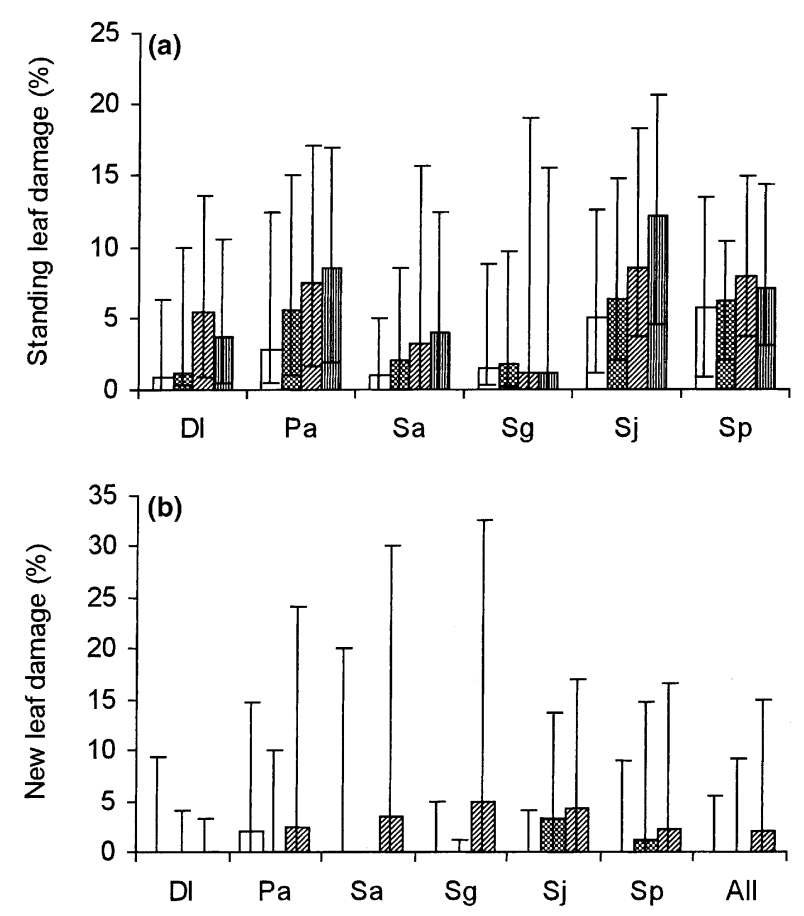

Figure 3. (a) Standing levels of leaf damage, median and interquartile range. Census 1 (unshaded), census 2 (cross-hatching), census 3 (diagonal hatching) and census 4 (vertical hatching). (b) Damage to new leaves, median and interquartile range. Period 1 (white bars), period 2 (shaded bars) and period 3 (diagonal hatching). $\mathrm{Dl}=D$. lanceolata, $\mathrm{Pa}=$ Parashorea spp., $\mathrm{Sa}=S$. acuminatissima, $\mathrm{Sg}=S$. glaucescens, $\mathrm{Sj}=S$. johorensis, $\mathrm{Sp}=S$. parvifolia, All = all species combined. Missing bars indicate zero median.

Model, $\mathrm{P}<0.001$ ), but not on topography. Seedlings lost and gained up to 10 leaves between censuses, but the distribution was highly skewed with most seedlings neither gaining nor losing leaves between censuses. Estimated leaf area was greatest in D. lanceolata and Parashorea (General Linear Model with Tukey's Honestly Significant Difference test, $\mathrm{P}<0.05)$. Leaf area was strongly related to seedling height $(r=0.44, \mathrm{P}<0.001)$, partly explaining the larger leaf area of $D$. lanceolata and Parashorea. The largest increases in leaf area per seedling between the first and last census were seen in D. lanceolata $(57 \% \pm 13$ SE), followed by $S$. johorensis (47\% \pm 17 SE) and Parashorea $(38 \% \pm 10 \mathrm{SE})$. Shorea acuminatissima, S. parvifolia and $S$. glaucescens showed no significant increase (paired samples t-test, $\mathrm{P}>0.3$ ). Increases in leaf area were seen in all species at a population level, because seedlings with fewer leaves were more likely to die (Figure 4a). There were no clear or consistent influences of topography on leaf area, once height had been controlled for.

Leaf loss and gain were positively correlated with total number of leaves (Spearman's $\rho, \mathrm{P}<0.001$ ), so relative monthly leaf gain and loss (RMLG and RMLL, respectively) were calculated as the number of leaves lost and gained in each census period divided by the original number of leaves and the time between censuses. Topography did not influence leaf turnover, though species did (Kruskal-Wallis test, $\mathrm{P}>0.001$ ). Shorea johorensis and Parashorea gained the most leaves and $S$. glaucescens the least (Figure 4b). Shorea johorensis lost the most leaves, S. glaucescens and S. acuminatissima the fewest (Figure 4c). Both RMLG and RMLL were greatest between the second and third census (Wilcoxon signed ranks test, $\mathrm{P}<$ $0.001)$. The density of newly flushed leaves in the understorey was also significantly greater in the second period (median 9 leaves $\mathrm{m}^{-2}$ ) compared with the first period (median 4 leaves $\mathrm{m}^{-2}$ ) and third period (median 5.8 leaves $\mathrm{m}^{-2}$, Wilcoxon signed ranks test, $\left.\mathrm{P}<0.05\right)$. Relative monthly net leaf change (RMNLC) for all seedlings combined, calculated as the net difference in leaf number between censuses over the original number of leaves and period in months, was lower in the last period compared with the previous ones (Figure 4d, paired samples t-test, $\mathrm{P} \leq 0.001)$.

Leaf damage was a significant predictor of abscission by the next census (Figure 5a, logistic regression, $\mathrm{P}<$ $0.001)$. In the first and third periods, leaves with less than $10 \%$ damage had survival rates of more than $90 \%$, while in the second census this fell to $\sim 70 \%$. Leaves with more than $50 \%$ damage had survival rates of $60-75 \%$ in the first and last periods, while in the second period survival was $52 \%$.

\section{Seedling survival}

Seedling density varied from 5 to $32 \mathrm{~m}^{-2}$. Mortality was greatest between March and September 1998 for all species except $S$. acuminatissima, which showed high, but decreasing, survival rates through the study (Figure 6, likelihood ratio test, $\mathrm{P}<0.05$ ).

Logistic regression was used to determine the influence of different factors on survival in each of the three census periods. Differences between census periods were sought using likelihood ratio tests. Survival was calculated as the proportion of seedlings remaining from the previous census. Significance level was set at $\mathrm{P} \leq 0.01$ since the effects of 42 factors were tested, i.e. three census periods, six species, four sites, topography, height, mean leaf damage and leaf number. Leaf damage, leaf number and census were significantly related to survival. Seedlings with more leaves and less leaf damage were more likely to survive, and survival was lowest between the second and third census. In the first and third measurement periods, seedlings with less than $10 \%$ leaf damage had more than $80 \%$ survival rates, whilst those with more than $50 \%$ damage had $\sim 50 \%$ survival (Figure $5 \mathrm{~b}$ ).

Topography had no significant overall influence on survival, though some parts of the steep slopes of two sites had high mortality due to soil disturbance by emerging cicadas. On inspection, a number of dead seedlings were 

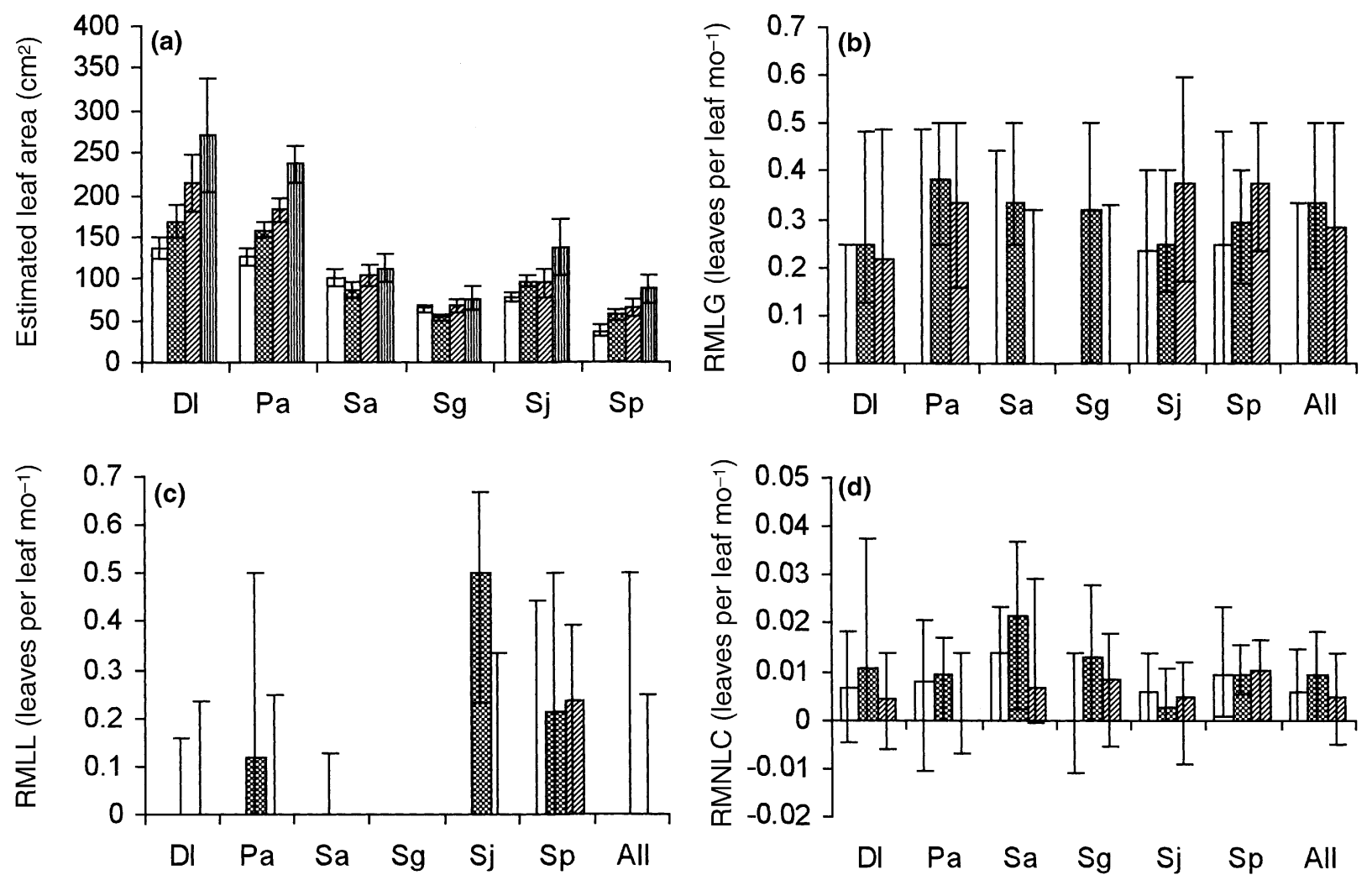

Figure 4. (a) Estimated leaf area, mean $\pm 95 \%$ confidence limits. Census 1 (unshaded), census 2 (cross-hatching), census 3 (diagonal hatching) and census 4 (vertical hatching). (b) Relative monthly leaf gain (RMLG), median and interquartile range. (c) Relative monthly leaf loss (RMLL), median and interquartile range. (d) Relative monthly net leaf change (RMNLC), median and interquartile range. Period 1 (unshaded), period 2 (cross-hatching) and period 3 (diagonal hatching). $\mathrm{Dl}=$ D. lanceolata, $\mathrm{Pa}=$ Parashorea $\mathrm{spp} ., \mathrm{Sa}=S$. acuminatissima, $\mathrm{Sg}=S$. glaucescens, $\mathrm{Sj}=$ S. johorensis, $\mathrm{Sp}=$ S. parvifolia, All = all species combined. Missing bars indicate zero median.

found to have been attacked by a scolytid beetle (Coleoptera: Scolytidae) root borer. This excavated the taproot and caused mortality in some areas (Bebber et al. 2002).

\section{Seedling growth}

Seedlings ranged from $7-79 \mathrm{~cm}$ in height. Through the study, seedlings growing on ridges were shorter than those growing on slopes and valleys (General Linear Model with Tukey's Honestly Significant Difference test, $\mathrm{P}<$ 0.001). Dryobalanops lanceolata seedlings were tallest, $S$. acuminatissima and S. parvifolia shortest (Figure 7). These rankings remained the same through the study (General Linear Model with Tukey's Honestly Significant Difference test, $\mathrm{P}<0.001$ ).

Seedlings grew under very dimly lit conditions of closed canopy, estimated GSF varying from $0.2-7.9 \%$ (mean $2.9 \% \pm 0.2 \mathrm{SE}$ ). GSF did not vary consistently with topography (General Linear Model, $\mathrm{P}>0.05$ ). Relative monthly height increment (RMHI) varied between -0.07 and $0.12 \mathrm{~cm} \mathrm{~cm}^{-1} \mathrm{mo}^{-1}$, i.e. some negative growth was measured. RMHI was significantly greater in the second period than in the third (Wilcoxon signed ranks test, $\mathrm{P}<$ 0.001). No relationship between mean RMHI per quadrat and GSF was detected (General Linear Model, P > 0.1), nor were there consistent effects of species, topographic position or leaf area.

\section{DISCUSSION}

GSF values were similar to those found under other closed-canopy primary tropical lowland forests (Becker \& Smith 1990, Canham et al. 1990, Chazdon \& Fetcher 1984, Clark et al. 1996, Nicotra et al. 1999). Under such conditions, seedling growth essentially ceases and leaf turnover is limited (Clark \& Clark 1985, Ng 1992, Whitmore \& Brown 1996), as was observed in the present study. Relative growth and leaf gain were elevated during the driest part of the study, as were mortality and leaf loss. Holmgren et al. (2001) suggest that tropical tree seedling recruitment is promoted by El Niño-related drought, because mortality and leaf abscission in canopy trees increase light and water availability in the understorey (Becker \& Smith 1990). This may explain elevated rates of leaf flushing, but it seems that the drought was severe 

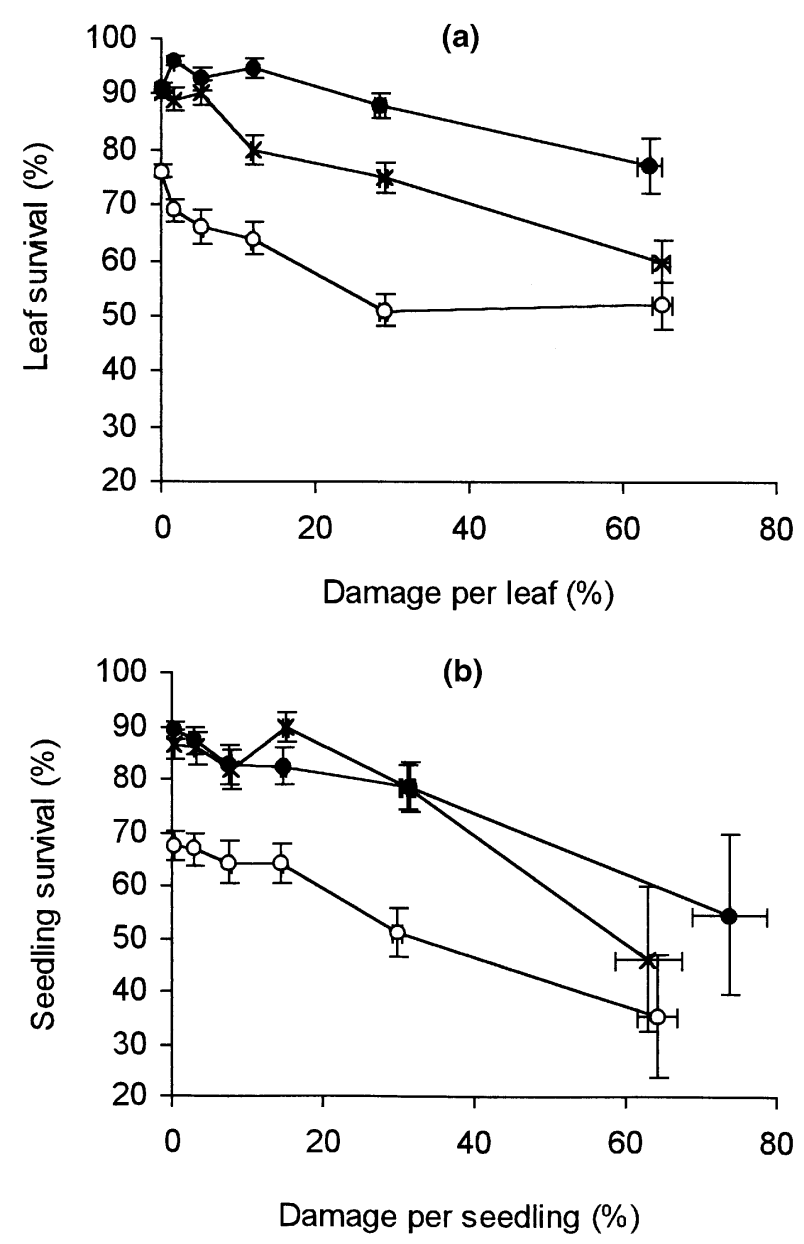

Figure 5. (a) Damage per leaf against proportion of leaves surviving to next census, mean $\pm 95 \%$ confidence limits. (b) Mean leaf damage per seedling against proportion of seedlings surviving to next census, mean $\pm 95 \%$ confidence limits. Damage classes are $<1 \%, 1-5 \%, 6-10 \%, 11-$ $20 \%, 21-50 \%$ and $51-100 \%$. Period $1(\square)$, period $2(\times)$ and period 3 (○).

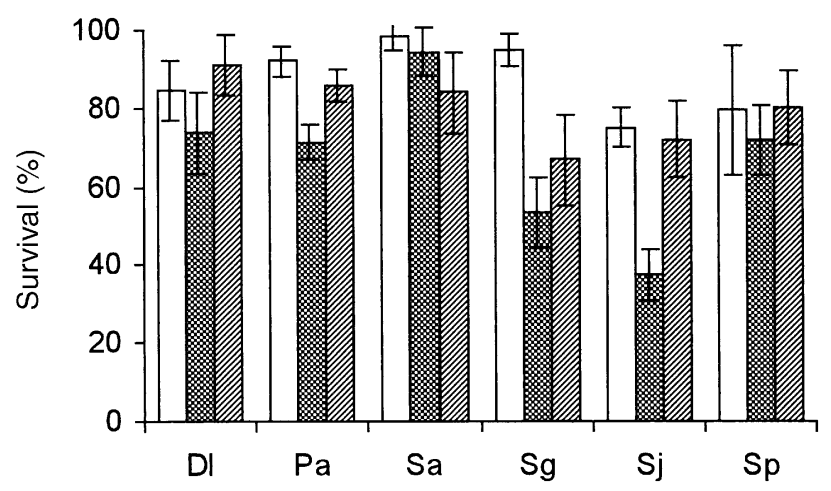

Figure 6. Proportion of seedlings surviving from the previous census \pm 95\% confidence limits. Period 1 (unshaded), period 2 (cross-hatching) and period 3 (diagonal hatching). $\mathrm{Dl}=D$. lanceolata, $\mathrm{Pa}=$ Parashorea spp., $\mathrm{Sa}=S$. acuminatissima, $\mathrm{Sg}=S$. glaucescens, $\mathrm{Sj}=S$. johorensis, $\mathrm{Sp}=$ S. parvifolia .

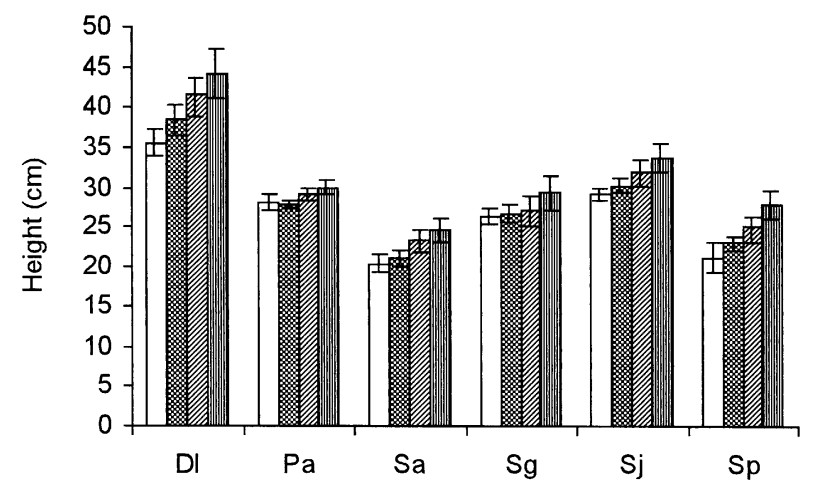

Figure 7. Seedling height through the study, mean $\pm 95 \%$ confidence limits. Census 1 (unshaded), census 2 (cross-hatching), census 3 (diagonal hatching) and census 4 (vertical hatching). $\mathrm{Dl}=$ D. lanceolata, $\mathrm{Pa}=$ Parashorea spp., $\mathrm{Sa}=S$. acuminatissima, $\mathrm{Sg}=S$. glaucescens, $\mathrm{Sj}=$ S. johorensis, $\mathrm{Sp}=S$. parvifolia.

enough to simultaneously increase leaf abscission, since leaf abscission is a physiological response to water deficit (Pallardy \& Rhoads 1993, Parker \& Pallardy 1985).

The effects of topographic variation in water availability were unclear. Ashton et al. (1995) found that dipterocarp seedling growth in a Sri Lankan rain forest was slowest on ridges in comparison with slopes and valleys, and for some species survival was least on ridges. Ridge sites are more drought-prone than lower slopes (Ashton 1992, Gibbons 1998), which may explain the smaller size of seedlings growing on ridges. Topography exerted no other strong or consistent influences on seedling performance in the present study.

Seedling mortality was higher during the driest period of the study than in the other periods. Previous studies have implicated drought as an agent in dipterocarp seedling mortality (Kachi et al. 1995, Turner 1990), though not in relation to ENSO. The most obvious sign of drought-related wilting and death was seen in Parashorea seedlings on one site, which was accompanied by an outbreak of root-boring beetles (Bebber et al. 2002). Survival was also related to leaf number. Dryobalanops lanceolata seedlings were tallest and leafiest, and this species showed the largest increases in growth and accumulation of leaf area. The architecture of $D$. lanceolata is thought to increase interception of sunflecks (Zipperlen \& Press 1996). Seed size can be an important determinant of seedling size and shade tolerance (Saverimuttu \& Westoby 1996, Walters \& Reich 2000), and there is some evidence for this in dipterocarps (Basada 1979). The large size of $D$. lanceolata seedlings in the present study may be related to the large, lipid-rich seeds of this species (Ichie et al. 2001). Energy reserves provided by large seeds can allow seedlings to recover from shoot damage (Harms \& Dalling 1997), but this has been suggested as unlikely in dipterocarps since these reserves are depleted by the time the first leaves are formed (Ichie et al. 2001). 
Of those species involved in the study, Dryobalanops lanceolata and Shorea glaucescens are classified as more shade-tolerant medium hardwoods, the other species as light hardwoods (Meijer \& Wood 1964). It has been suggested that shade-tolerant species have long-lived leaves which tend to be more heavily protected than the shortlived leaves of light-demanding species (Coley 1988). The two medium hardwoods had low levels of defoliation, as predicted, but $S$. acuminatissima seedlings were also lightly defoliated. Leaf turnover rates also partially support predictions based on timber group, in that $S$. glaucescens and D. lanceolata had low rates of leaf loss. However, S. acuminatissima also lost few leaves. Expected differences in survival were obscured by chance factors such as soil disturbance by emerging cicadas, that killed large numbers of $S$. glaucescens seedlings in one of the sites. Previous studies have shown that random variation in natural forest conditions obscure any niche differentiation between seedlings (Brokaw \& Busing 2000).

Rates and standing levels of defoliation were very similar to those of shade-tolerant species in other studies of humid tropical forests (Coley \& Barone 1996). Leaf damage was strongly related to abscission and seedling mortality. The effect of defoliation was seen in all species, and was not simply the result of the species-level correlation between leaf longevity and defence (Coley et al. 1985). It is possible that the influence of defoliation on mortality was indirect, causing increased abscission, reduced light interception and a negative energy balance. Damage-related abscission has been observed in temperate and tropical species, and may be the result of disruption of leaf development, an adaptive response to prevent pathogen infection and water loss, or because more carbon can be gained by flushing a new leaf than by retaining a damaged one (reviewed in Blundell \& Peart 2000). Defoliation may be particularly detrimental to seedlings in deep shade (Clark \& Clark 1985), since each leaf presents a larger proportion of available photosynthetic area compared with seedlings in high-light environments.

Leaf damage in the present study was inflicted by biotic agents, and the majority of defoliation occurred while the leaf was expanding (Coley \& Barone 1996). Damagerelated abscission is much more likely in expanding than mature leaves of dipterocarp seedlings (Blundell \& Peart 2000), and the influence of defoliation on abscission was therefore stronger than in studies in which mature leaves are artificially defoliated (e.g. Becker 1983).

Defoliation was unimportant to the vast majority of seedlings at any one time. However, seedlings may persist for several years under closed canopy (Delissio et al. 2002), increasing the probability of incurring severe damage. Low standing levels of defoliation may be due to the rarity of palatable young leaves (Basset 1999) or to the presence of large numbers of ants in the seedling layer (unpubl. data) that are likely to deter defoliators, since ants can be important predators in tropical forests (Floren et al. 2002, Novotny et al. 1999).

Rates of apical meristem damage were similar to other studies of dipterocarp seedlings (Becker 1983). There was some indication that meristem damage increased the probability of mortality, but this was not consistent through the study and has not been seen in previous studies (Clark \& Clark 1985). The proportion of seedlings with meristem damage was greatest in the last, wettest census period. Clark \& Clark (1985) suggest that this may be because meristem damage is primarily caused by fungal infections that are more likely during periods of high rainfall.

Interactions between herbivory and drought are likely to depend upon the responses of both insects and seedlings to reduced water availability. A greater number of palatable new leaves were produced during the driest period but defoliation rates were lower, as might be expected if drought led to a decrease in herbivore populations (Coley 1998). Also, leaf chewers perform poorly when plants are water-stressed (Koricheva et al. 1998). A moth-trapping study near the study area noted a severe decline in moth abundance during the drought, and subsequent recovery when rain returned $(H$. Barlow, pers. comm.).

The study showed that ENSO-related drought and herbivory influenced survival of dipterocarp seedlings in primary lowland forest. Only one drought episode was followed, so the results must be treated with some caution. However, the expected increase in the frequency of ENSO events will allow further study of this phenomenon in future.

\section{ACKNOWLEDGEMENTS}

We acknowledge the following for permission to conduct research in the Danum Valley, Sabah: Yayasan Sabah (Forestry Upstream Division), The Danum Valley Management Committee, The State Secretary (Internal Affairs \& Research Office), Sabah Chief Minister's Department and the Economic Planning Unit of the Prime Minister's Department, Kuala Lumpur. We thank Dr Chey Vun Khen (Head of Entomology Division, Forest Research Centre, Sepilok, Malaysia) for assistance in field studies. The study was funded by the Burtt Davey Research Scholarship, University of Oxford, UK.

\section{LITERATURE CITED}

APPANAH, S. 1993. Mass flowering of dipterocarp forests in the aseasonal tropics. Journal of Biosciences 18:457-474.

ASHTON, P. M. S. 1992. Some measurements of microclimate within a Sri Lankan tropical rainforest. Agricultural and Forest Meteorology 59:217-235.

ASHTON, P. M. S., GUNATILLEKE, C. V. S. \& GUNATILLEKE, I. 
A. U. N. 1995. Seedling survival and growth of four Shorea species in a Sri Lankan rainforest. Journal of Tropical Ecology 11:263-279.

BASADA, R. M. 1979. Effect of seed size on germination, seedling survival and height growth of white lauan (Shorea contorta Vidal). Sylvatrop 4:77-80.

BASSET, Y. 1999. Diversity and abundance of insect herbivores foraging on seedlings in a rainforest in Guyana. Ecological Entomology 24:245-259.

BEBBER, D. 2002. Dipterocarp susceptibility to drought: a role for wood structure? Journal of Tropical Forest Science 14:425-427.

BEBBER, D., BROWN, N. \& SPEIGHT, M. 2002. Drought and root herbivory in understorey Parashorea (Kurz) seedlings in Borneo. Journal of Tropical Ecology 18:795-804.

BECKER, P. 1983. Effects of insect herbivory and artificial defoliation on survival of Shorea seedlings. Pp. 241-252 in Sutton, S. L., Whitmore, T. C. \& Chadwick, A. C. (eds). Tropical rain forest: ecology and management. Blackwell Scientific Publications, Oxford.

BECKER, P. \& SMITH, A. P. 1990. Spatial autocorrelation of solar radiation in a tropical moist forest understory. Agricultural and Forest Meteorology 52:373-379.

BECKER, P., LYE ONG, C. \& GOH, F. 1998. Selective drought mortality of dipterocarp trees: no correlation with timber group distributions in Borneo. Biotropica 30:666-671.

BLUNDELL, A. G. \& PEART, D. R. 1998. Distance-dependence in herbivory and foliar condition for juvenile Shorea trees in Bornean dipterocarp rain forest. Oecologia 117:151-160.

BLUNDELL, A. G. \& PEART, D. R. 2000. High abscission rates of damaged expanding leaves: field evidence from seedlings of a Bornean rain forest tree. American Journal of Botany 87:1693-1698.

BROKAW, N. \& BUSING, R. T. 2000. Niche versus chance and tree diversity in forest gaps. Trends in Ecology and Evolution 15:183-188. BROWN, N. D. 1998. Out of control: fires and forestry in Indonesia. Trends in Ecology and Evolution 13:41.

BROWN, N. D., PRESS, M. C. \& BEBBER, D. 1999. Growth and survivorship of dipterocarp seedlings: differences in shade persistence create a special case of dispersal limitation. Philosophical Transactions of the Royal Society, London, Series B 354:1847-1856.

CANHAM, C. D., DENSLOW, J. S., PlATT, W. J., RUNKLE, J. R., SPIES, T. A. \& WHITE, P. S. 1990. Light regimes beneath closed canopies and tree-fall gaps in temperate and tropical forests. Canadian Journal of Forest Research 20:620-631.

CHAZDON, R. L. \& FETCHER, N. 1984. Light environments of tropical forests. Pp. 27-36 in Medina, E., Vázquez-Yánes, C. \& Mooney, H. A. (eds). Physiological ecology of plants of the wet tropics. Junk, The Hague.

CLARK, D. B. \& CLARK, D. A. 1985. Seedling dynamics of a tropical tree: impacts of herbivory and meristem damage. Ecology 66:18841892.

CLARK, D. B., CLARK, D. A., RICH, P. M., WEISS, S. \& OBERBAUER, S. F. 1996. Landscape-scale evaluation of forest structure and understory light environments in a neotropical lowland rain forest. Canadian Journal of Forest Research 26:747-757.

COLEY, P. D. 1988. Effects of plant growth rate and leaf lifetime on the amount and type of antiherbivore defense. Oecologia 74:531-536. COLEY, P. D. 1998. Possible effects of climate change on plant/herbi- vore interactions in moist tropical forests. Climatic Change 39:455472.

COLEY, P. D. \& BARONE, J. A. 1996. Herbivory and plants defenses in tropical forests. Annual Review of Ecology and Systematics 27:305335.

COLEY, P. D., BYRANT, J. P. \& CHAPIN, F. S. 1985. Resource availability and plant antiherbivore defence. Science 230:895-899.

CURRAN, L. M., CANIAGO, I., PAOLI, G. D., ASTIANTI, D., KUSNETI, M., LEIGHTON, M., NIRARITA, C. E. \& HAERUMAN, H. 1999. Impact of El Niño and logging on canopy tree recruitment in Borneo. Science 286:2184-2188.

DELISSIO, L. J., PRIMACK, R. B., HALL, P. \& LEE, H. S. 2002. A decade of canopy-tree seedling survival and growth in two Bornean rain forests: persistence and recovery from suppression. Journal of Tropical Ecology 15:645-658.

FLOREN, A., BIUN, A. \& LINSENMAIR, K. E. 2002. Arboreal ants as key predators in tropical lowland rainforest trees. Oecologia 131: $137-144$.

GIBBONS, J. 1998. Water relations, phenology and drought adaptation of understorey trees in tropical lowland rain forest. Unpublished Ph.D. dissertation, University of Stirling.

GLYNN, P. W. 1988. El Niño-Southern Oscillation 1982-1983: nearshore population, community, and ecosystem responses. Annual Review of Ecology and Systematics 19:309-345.

HARMS, K. E. \& DALLING, J. W. 1997. Damage and herbivory tolerance through resprouting as an advantage of large seed size in tropical trees and lianas. Journal of Tropical Ecology 13:617-621.

HOLMGREN, M., SCHEFFER, M., EZCURRA, E., GUTIERREZ, J. R. \& MOHREN, G. M. J. 2001. El Niño effects on the dynamics of terrestrial ecosystems. Trends in Ecology and Evolution 16:89-94.

ICHIE, T., NINOMIYA, I. \& OGINO, K. 2001. Utilization of seed reserves during germination and early seedling growth by Dryobalanops lanceolata (Dipterocarpaceae). Journal of Tropical Ecology 17:371-378.

KACHI, N., OKUDA, T. \& YAP, S. K. 1995. Effect of herbivory on seedling establishment of Dryobalanops aromatica (Dipterocarpaceae) under plantation forest in Peninsular Malaysia. Journal of Tropical Forest Science 8:59-70.

KORICHEVA, J., LARSSON, S. \& HAUKIOJA, E. 1998. Insect performance on experimentally stressed woody plants: a meta analysis. Annual Review of Entomology 43:195-216.

MARSH, C. \& GREER, A. G. 1992. Forest land-use in Sabah, Malaysia: an introduction to the Danum Valley. Philosophical Transactions of the Royal Society of London, Series B 335:331-340.

MATTSON, W. J. \& HAACK, R. A. 1987. The role of drought stress in provoking outbreaks of phytophagous insects. Pp. 365-407 in Barbosa, P. \& Schultz, J. C. (eds). Insect outbreaks. Academic Press, London.

MEIJER, W. \& WOOD, G. H. S. 1964. Dipterocarps of Sabah. Forest Department, Sandakan. 344 pp.

NAKAGAWA, M., TANAKA, K., NAKASHIZUKA, T., OHKUBO, T., KATO, T., MAEDA, T., SATO, K., MIGUCHI, H., NAGAMASU, H., OGINO, K., TEO, S., HAMID, A. A. \& LEE, H. S. 2000. Impact of severe drought associated with the 1997-8 El Niño in a tropical forest in Sarawak. Journal of Tropical Ecology 16:355-367. 
NG, F. S. P. 1992. Leaf senescence in kapur (Dryobalanops aromatica, Dipterocarpaceae) under different canopy conditions. Journal of Tropical Forest Science 4:275-280.

NICOTRA, A. B., CHAZDON, R. L. \& IRIARTE, S. V. B. 1999. Spatial heterogeneity of light and woody seedling regeneration in tropical wet forests. Ecology 80:1908-1926.

NOVOTNY, V., BASSET, Y., AUGA, J., BOEN, W., DAL, C., DROZD, P., KASBAL, M., ISUA, B., KUTIL, R., MANUMBOR, M. \& MOLEM, K. 1999. Predation risk for herbivorous insects on tropical vegetation: a search for enemy-free space and time. Australian Journal of Ecology 24:477-483.

PALLARDY, S. G. \& RHOADS, J. L. 1993. Morphological adaptations to drought in seedlings of deciduous angiosperms. Canadian Journal of Forest Research 23:1766-1774.

PARKER, W. C. \& PALLARDY, S. G. 1985. Drought-induced leaf abscission and whole-plant drought tolerance of seedlings of seven black walnut families. Canadian Journal of Forest Research 15:818821 .

SAVERIMUTTU, T. \& WESTOBY, M. 1996. Seedling longevity under deep shade in relation to seed size. Journal of Ecology 84:681-689.

TIMMERMANN, A., OBERHUBER, J., BACHER, A., ESCH, M., LATIF, M. \& ROECKNER, E. 1999. Increased El Niño frequency in a climate model forced by future greenhouse warming. Nature 398: 694-697.

TURNER, I. M. 1990. The seedling survivorship and growth of three Shorea spp. in a Malaysian tropical rain forest. Journal of Tropical Ecology 6:469-478.

TURNER, I. M. 2001. The ecology of trees in the tropical rain forest. Cambridge University Press, Cambridge. 298 pp.

WALSH, R. P. D. 1996. Drought frequency changes in Sabah and adjacent parts of northern Borneo since the late nineteenth century and possible implications for tropical rain forest dynamics. Journal of Tropical Ecology 12:385-407.

WALSH, R. P. D. \& NEWBERY, D. M. 1999. The ecoclimatology of Danum, Sabah, in the context of the world's rainforest regions, with particular reference to dry periods and their impact. Philosophical Transactions of the Royal Society, London, Series B 354:1869-1883.

WALTERS, M. B. \& REICH, P. B. 2000. Seed size, nitrogen supply, and growth rate affect tree seedling survival in deep shade. Ecology 81:1887-1901.

WARING, G. L. \& COBB, N. S. 1992. The impact of plant stress on herbivore population dynamics. Pp. 168-187 in Bernays, E. E. (ed.). Insect-plant interactions vol. 4. CRC Press, Boca Raton.

WEBB, C. O. \& PEART, D. R. 1999. Seedling density dependence promotes co-existence of Bornean rain forest trees. Ecology 80:20062017.

WHITMORE, T. C. 1984. Tropical rain forests of the Far East. (Second Edition). Clarendon Press, Oxford. 352 pp.

WHITMORE, T. C. \& BROWN, N. D. 1996. Dipterocarp seedling growth in rain forest canopy gaps during six and a half years. Philosophical Transactions of the Royal Society, London, Series B 351: 1195-1203.

WOODS, P. 1989. Effects of logging, drought and fire on structure and composition of tropical forests in Sabah, Malaysia. Biotropica 21:290-298.

YASUDA, M., MATSUMOTO, J., OSADA, N., ICHIKAWA, S., KACHI, N., TANI, M., OKUDA, T., FURUKAWA, A., ABDUL RAM, N., MANOKARAN, N. \& NIK, A. R. 1999. The mechanism of general flowering in Dipterocarpaceae in the Malay Peninsula. Journal of Tropical Ecology 15:437-449.

ZIPPERLEN, S. W. \& PRESS, M. 1996. Photosynthesis in relation to growth and seedling ecology of two dipterocarp rain forest tree species. Journal of Ecology 84:863-876. 
